\title{
Transnational Accessibility between Residential Areas Based on Multimodal Transport System
}

\author{
Nan Xia ${ }^{1,2,3, *}$, Liang Cheng ${ }^{1,2,4}$ and Manchun $\mathrm{Li}^{1,2,4}$ \\ 1 Jiangsu Provincial Key Laboratory of Geographic Information Technology, School of Geography and Ocean \\ Science, Nanjing University, Nanjing 210093, China; lcheng@nju.edu.cn (L.C.); manchun@nju.edu.cn (M.L.) \\ 2 Department of Geographic Information Science, Nanjing University, Nanjing 210093, China \\ 3 Fenner School of Environment and Society, Australian National University, Canberra, ACT 2601, Australia \\ 4 Collaborative Innovation Center for the South Sea Studies, Nanjing University, Nanjing 210093, China \\ * Correspondence: xianan@nju.edu.cn
}

check for updates

Citation: Xia, N.; Cheng, L.; Li, M. Transnational Accessibility between Residential Areas Based on Multimodal Transport System. ISPRS Int. J. Geo-Inf. 2021, 10, 136. https:// doi.org/10.3390/ijgi10030136

Academic Editors: Wolfgang Kainz and Giuseppe Borruso

Received: 6 January 2021

Accepted: 1 March 2021

Published: 4 March 2021

Publisher's Note: MDPI stays neutral with regard to jurisdictional claims in published maps and institutional affiliations.

Copyright: (c) 2021 by the authors. Licensee MDPI, Basel, Switzerland. This article is an open access article distributed under the terms and conditions of the Creative Commons Attribution (CC BY) license (https:/ / creativecommons.org/licenses/by/ $4.0 /)$.

\begin{abstract}
Due to the development of globalization, transnational activities are more frequent and evaluations of current accessibility are the basis for accessibility improvements. Accessibility evaluation indices generally contain two parts: travel time and travel probability. However, complex transnational processes involve the multimodal transport system, including air and land transport networks, which makes the calculation of these indices more difficult because large quantities of fundamental data, in addition to suitable models, are needed. In this study, residential areas were set as the basic evaluation unit for fine-scale and whole-process analysis. Then, multiple web-sourced platforms were introduced to acquire the travel time between each pair of residential areas. The temporal-range radiation model was applied to calculate transnational travel probability by considering spatial interactions of populations. Finally, the weighted-average travel time to South Asia and Southeast Asia (SA\&SEA) countries was generated to represent the overall accessibility for each populated area in China. The results showed that China had better accessibility to SEA than SA, and countries with high accessibility were Thailand, Singapore, and Malaysia. In China, southwest, south, and southeast regions showed larger accessibility to SA\&SEA. Improvements of accessibility were also indicated by conjoint analysis of airport nodes. The proposed framework can help to delineate the spatial patterns of transnational accessibility and guide the enhancements of accessibility.
\end{abstract}

Keywords: transnational accessibility; population; web-sourced data; temporal-range radiation model; residential areas

\section{Introduction}

Due to the development of globalization, transnational transportation activities have become frequent and permanent, and are essential to political exchanges, trade contacts, cultural exchanges, and daily lives [1-3]. The evaluation of current accessibility is a priority for the analysis, improvement, and planning of transportation system [4,5]. Accessibility is generally defined as the ease of access to activities by overcoming some impediment [6,7], and is well recognized to represent the spatial relationships in various transport networks $[8,9]$. The air transport network (ATN) is the basis for population and commodity connectivity at large scales, especially for transnational processes, and several existing studies have addressed airport-to-airport accessibility [10-12]. However, the original departure place is the residential area instead of the airport, and travels between residential areas and airports via the land transport network (LTN) should not be ignored $[13,14]$. Thus, considerations of the multimodal transport system (ATN and LTN, Figure 1) between residential areas are necessary for the fine-scale and whole-process analysis of transnational accessibility [15-18]. 


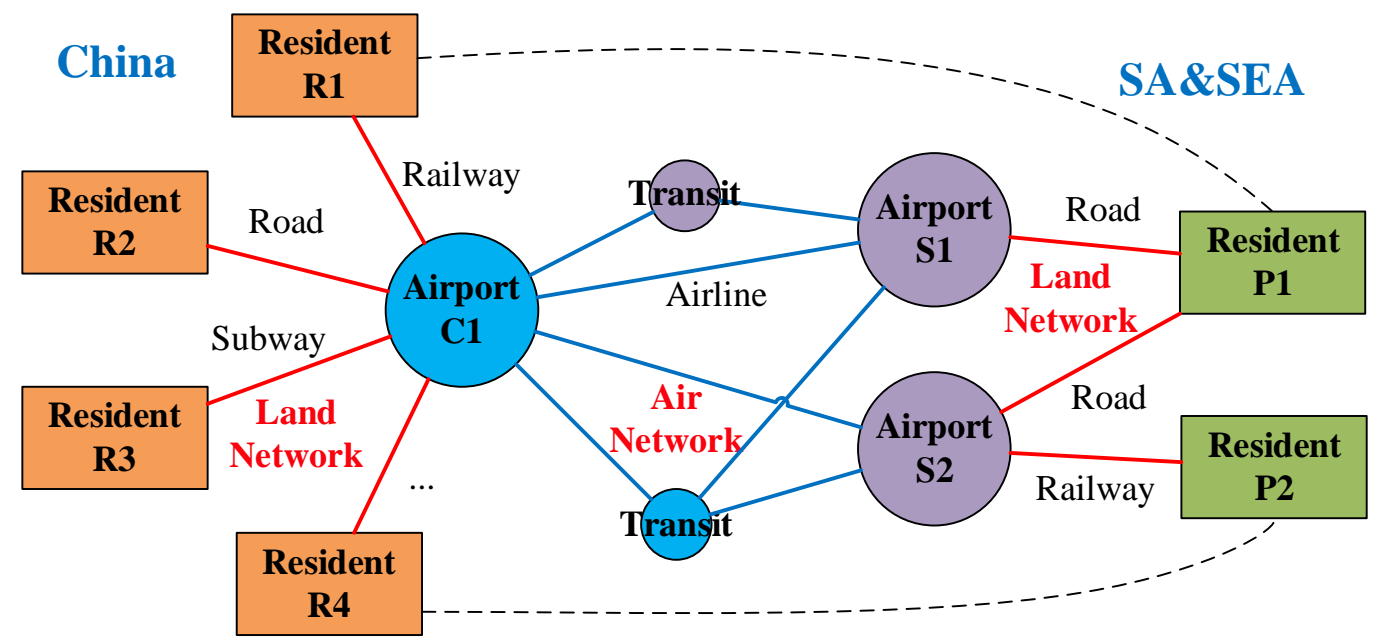

Figure 1. The explanation of the transnational travel from China residential areas to South Asia and Southeast Asia (SA\&SEA) residential areas, including air and land transport networks.

To measure accessibility, various quantitative indicators have considered which fall into two broad categories: travel cost and potential opportunities for interaction [7,19]. For travel cost, the minimum travel time between an origin and a destination is regarded as the most relevant indicator $[20,21]$. Thus, the travel time between transnational residential areas mainly contains two parts: the ATN travel time between airports, and the LTN travel time between residential areas and target airports (Figure 1). Due to the rapid development of online technology, travel time can be directly acquired from online platforms, simplifying geographical data collection and processing [22,23]. Unfortunately, LTN and ATN travel time cannot be simultaneously acquired from a single platform. For LTNs, Google Maps provides an application programming interface (API) for travel time queries between an arbitrary origin and destination with mixed travel modes, such as walking, driving, and public transit [24-26]. For ATNs, third-party online booking platforms provide detailed flight information with different airline choices between airports. Considering the daily changes of flight arrangements, the web crawling method can be used to gather a large amount of dynamic daily flight information $[27,28]$. The use of both of these online data sources allows the overall transnational travel time via ATNs and LTNs to be determined.

The interaction opportunities are broadly defined as the frequency or possibility for spatial interactions, and the travel probability or population is the most effective indicator $[29,30]$. Amongst all relevant indicators, the actual population that participates in transnational travel is challenging to determine due to data privacy issues and passenger diversion within ATNs [11,31]. Thus, the spatial interaction model, which requires less observation data, was introduced to estimate the spatial pattern of travel probability, and to simulate the physical processes that make it more reliable $[32,33]$. Several models have been applied to estimate travel probability, including lognormal, Poisson, and gravity models, which require a priori data or socioeconomic data [12,34]. Due to its parameterfree nature, the radiation model, which is analogous to particle movements, performs well in population flow estimations when previous mobility data are lacking $[32,35]$. This model has been successfully applied in various contexts, such as epidemic spread, population mobility, and city planning [33,36,37].

The radiation model assumes that the potential population flow is positively correlated with the total population in the origin and destination places, and individuals tend to be absorbed by spatially adjacent populated areas [32]. However, "spatial adjacent areas" are defined as simple circular regions without the consideration of geographical obstacles, including lakes and mountains. Because travel time is the most efficient cost indicator, a modified temporal-range radiation model was applied in this study, turning simple spatial adjacency into irregularly shaped "temporal adjacent areas" [38]. The temporal range for the radiation model is consistent with the travel time for the travel cost indicator, and is 
strongly correlated with the Manhattan distance in transport networks. The temporal-range radiation model has proven successful in estimating the spatial pattern of travel population at large scales, such as national and continental scales [37,38]. However, the temporal-range radiation model has rarely been applied in large-scale accessibility research or, in particular, transnational accessibility research. In addition, complex transnational travel contains multiple segmented processes, and the identification of adjacent areas for the radiation model is also different from that for single transport network.

To evaluate large-scale or transnational accessibility, travel time and travel probability/population should be integrated to generate an overall evaluation indicator, wherein the travel probability/population is set as a weight index $[39,40]$. One commonly used model is the weighted-average method, which can integrate two or more indexes with different semantics [41,42]. The model is widely used in network analysis, and a smaller weighted cost value indicates higher overall accessibility [42]. Two common forms are the population-weighted travel time/distance index [30] and travel probability/populationweighted travel time/distance index [43]. Although previous research has suggested that the travel probability/population-weighted accessibility index is superior [44], the weightedaverage travel time index is seldom applied in transnational accessibility research.

China launched the "Silk Road Economic Belt and the 21st-Century Maritime Silk Road Initiative" (B\&R) in 2014, aiming at promoting multifaceted collaborations between China and surrounding areas [2]. South Asia and Southeast Asia (SA\&SEA) have direct spatial relationships with China, and the evaluation of transnational accessibility is urgently needed between China and SA\&SEA. Notably, the transnational LTNs are complex and were not considered in this study, and the accessibility indices are calculated between China and each SA\&SEA country. Due to the difficulty of calculating the accessibility indices of the transnational travel and multimodal transport system, including data acquisition and model adaption, the research aims of this study were to: (1) construct the accessibility indices between residential areas under the multimodal transport system, with travel time from multiple online platforms and travel probability using the temporal-range radiation model; (2) evaluate the overall transnational accessibility between China and SA\&SEA for application demonstration.

In Section 2, the study area and materials used in this article are described. In Section 3, the methodology is described. Section 4 contains the main results and findings. A discussion is presented in Section 5. Our conclusions are presented in Section 6.

\section{Study Area and Materials}

\subsection{Study Area}

The study area included China, South Asia (SA), and Southeast Asia (SEA). China has a land area of $963.41 \times 10^{4} \mathrm{~km}^{2}$ (square kilometers), with a population of 1.41 billion in 2015. South Asia comprises 7 countries and covers a land area of about $443.93 \times 10^{4} \mathrm{~km}^{2}$ with a population of 1.71 billion in 2015 (Table 1). Southeast Asia contains 11 countries, covering a land area of $448.25 \times 10^{4} \mathrm{~km}^{2}$ with a population of 0.63 billion in 2015 (Table 1). To construct the inter-regional ATN, we selected the 65 busiest civil international airports in China (including Hong Kong, Macao, and Taiwan), which account for $93.08 \%$ of the total passenger flows in China [45] (Figure 2). Beijing, Shanghai, and Taipei each have two international airports, with International Air Transport Association (IATA) codes of PEK/NAY, SHA/PVG, and TPE/TSA, respectively (refer to https:/ / www.iata.org/ en/publications / directories / code-search/, accessed on 10 May 2018). Correspondingly, 63 main airports in SA\&SEA offered service to China in 2017, of which 13 were located in SA and 50 in SEA (Figure 2). Thailand, Indonesia, and India contained the largest number of navigable airports (flight routes/flights between airports) with China, with about 14, 8 , and 6 , respectively. 
Table 1. The name abbreviation (Abbr), area, 2015 population (Pop_2015), number of residential points (No. of RP), and number of selected airports (No. of AP) for China (EA, East Asia), 8 countries in South Asia (SA) and 10 countries in Southeast Asia (SEA).

\begin{tabular}{|c|c|c|c|c|c|c|}
\hline Country & Abbr & Region & $\begin{array}{c}\text { Area } \\
\left(\mathbf{1 0}^{4} \mathrm{~km}^{2}\right)\end{array}$ & $\begin{array}{l}\text { Pop_2015 } \\
\left(10^{4}\right)\end{array}$ & No. of RP & No. of AP \\
\hline China & $\mathrm{CHN}$ & EA & 963.41 & $140,730.56$ & 44,682 & 65 \\
\hline Bangladesh & BGD & SA & 14.03 & $16,099.56$ & 544 & 1 \\
\hline Bhutan & BTN & SA & 4.01 & 77.48 & 205 & 1 \\
\hline India & IND & SA & 316.70 & $131,105.05$ & 5967 & 6 \\
\hline Sri Lanka & LKA & SA & 6.63 & 2071.52 & 13,941 & 1 \\
\hline Maldives & MDV & SA & 0.03 & 35.88 & 250 & 1 \\
\hline Nepal & NPL & SA & 14.82 & 2851.37 & 3990 & 1 \\
\hline Pakistan & PAK & $\mathrm{SA}$ & 87.71 & $18,892.48$ & 396 & 2 \\
\hline Brunei & $\mathrm{BRN}$ & SEA & 0.58 & 42.32 & 40 & 1 \\
\hline Indonesia & IDN & SEA & 190.11 & $25,756.38$ & 498 & 8 \\
\hline Cambodia & KHM & SEA & 18.25 & 1557.79 & 1621 & 3 \\
\hline Laos & $\mathrm{LAO}$ & SEA & 23.11 & 680.20 & 140 & 4 \\
\hline Burma & MMR & SEA & 67.26 & 5389.72 & 326 & 3 \\
\hline Malaysia & MYS & SEA & 33.15 & 3033.10 & 932 & 5 \\
\hline Philippines & PHL & SEA & 29.58 & $10,069.91$ & 41,954 & 4 \\
\hline Singapore & SGP & SEA & 0.07 & 559.82 & 55 & 1 \\
\hline Thailand & THA & SEA & 51.62 & 6795.94 & 927 & 13 \\
\hline Timor-Leste & TLS & SEA & 1.50 & 131.45 & 442 & 1 \\
\hline Vietnam & VNM & SEA & 33.02 & 9344.76 & 688 & 7 \\
\hline
\end{tabular}

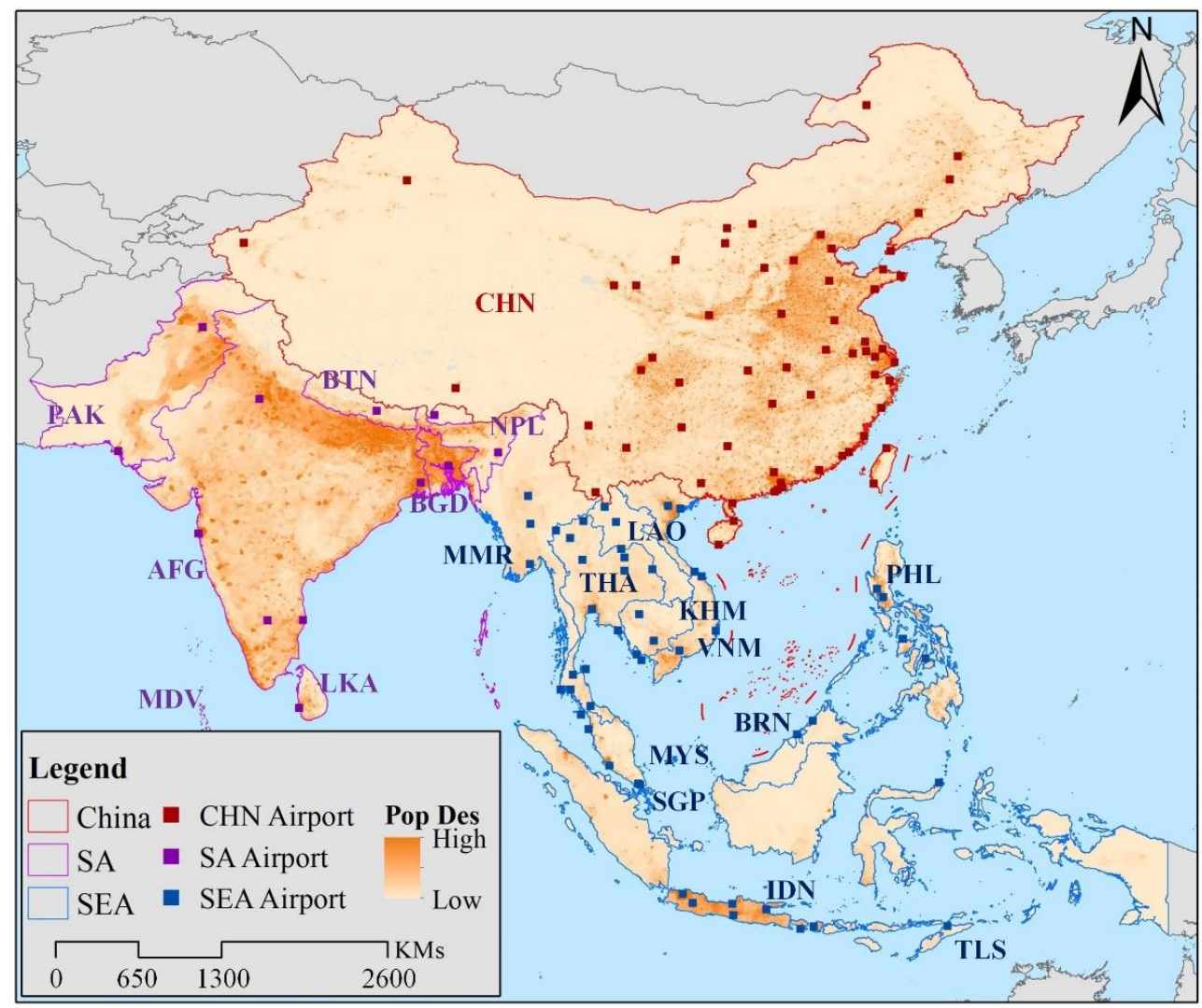

Figure 2. The spatial distribution of the 65 busiest airports in China (including Hong Kong, Macao, and Taiwan), and the main 63 navigable airports in South Asia (SA) and Southeast Asia (SEA). The grid population data is also shown for better representation than residential point data [46]. The figure is under WGS-84 geographical coordinate system. 


\subsection{Materials}

\subsubsection{Resident Population Point Data}

The estimated resident population point data for 2015, adjusted by the United Nations, were acquired from the Center for International Earth Science Information Network [46] (Figure 2). The point location information mostly represents the geometric center of each populated administrative unit (village or town), and the property contains the estimated population of each unit. This data includes 44,682 residential points in China, 25,293 residential points in SA, and 47,623 residential points in SEA (Table 1). The point density for different regions varies slightly due to different spatial granularities for the original administrative units.

\subsubsection{Web-Sourced Flight Information for ATN}

Information available from online booking platforms contains daily airline schedules, travel time, and flight arrangements. Online booking is the main pathway for the purchase of plane tickets in China, accounting for $59.2 \%$ of the market, and third-party platforms, including Qunar, Alitrip, and Ctrip, account for the largest online market share. These three platforms offer authoritative and complete flight information, and were selected as the data sources. The web crawling method was introduced to obtain relevant flight information, such as departure airport, departure time, flight duration, flight layover information, arrival time, and arrival airport, without associated commercial information, such as price and ticket information. For non-direct flight routes, the layover time was included within the total flight time. The small amount of error information for ATN, caused by the network, web crawler, or web page, were removed to ensure the data quality according to network return message. Flight information from China airports to SA\&SEA airports was acquired for a two-month period from 1 June to 30 August 2017, because this is the busiest travel period in this region.

\subsubsection{Web Mapping API Data for LTN}

LTN travel time can be directly acquired from the open-access web mapping APIs, including the Baidu Maps API for China and the Google Maps API for SA\&SEA regions. Baidu Maps offers superior and more up-to-date geographical information on China, including high-speed railways and highways. The latitude/longitude coordinates of residential points and airport points in the WGS84 coordinate system were transformed into the "bd09" Baidu Maps coordinate system (http:/ / lbsyun.baidu.com/index.php?title= webapi/guide/changeposition, accessed on 10 May 2018). Then these "bd09" coordinates were input into the Baidu "Direction" API queries (http:/ / lbsyun.baidu.com/index.php? title=webapi / direction-api-v2, accessed on 10 May 2018). The API can directly return precise travel time using optimal forms of public transit (i.e., railway, subway, and intercity bus) and driving modes. Public transport time was prioritized for consideration and driving time was only adopted in cases where public transit was unavailable. The same method was applied for the SA\&SEA region using the Google Maps "Directions" API (https:/ / developers.google.cn/maps/documentation/directions/, accessed on 10 May 2018), and only travel time within individual countries was considered. The travel time generated by the two APIs reflected historic averages, and standardized query time was set to minimize daily time changes: morning (8-10 a.m.), afternoon (12-13 p.m.), and evening (5-7 p.m.) on weekdays. These three time slots represent daily variations within transport systems, and thus yield more reliable average values [25].

\section{Methods}

The systematic framework included three main parts: (1) calculate the minimum total travel time between residential areas by integrating LTN and ATN travel time; (2) construct the temporal-range radiation model by identifying the temporal range and calculate the travel probability; and (3) propose the weighted-average travel time to represent the overall accessibility between China and SA\&SEA at national scales. 


\subsection{Total Travel Time between Residential Areas}

Travel time between residential areas contained both LTN travel time and ATN travel time, without considering waiting time between LTN and ATN. The calculation of the minimum total travel time from China residential area $i$ to SA\&SEA residential area $j$ was divided into the following three steps:

(1) LTN travel time. For a certain residential area, there might be several airports within a reasonable travel time. The airport with the least LTN travel time from a residential area might have a large ATN travel time due to the lack of direct flight routes. Thus, a maximum of five airports with the least LTN travel time were selected as alternative airports. The transnational LTNs were not considered in this study and LTN travel time was calculated within only one country.

(2) ATN travel time. The daily average flight time of direct and non-direct flight routes was first calculated separately based on 60 days of data (Equation (1)). Then the ATN travel time from China airport $A P 1$ to SA\&SEA airport AP2 ( $\left.t_{A P 1 \_A P 2}\right)$ was set as the minimum value of these two daily average values. Thus, we constructed a [65 $\times 63]$ two-dimensional matrix, representing ATN travel time from 65 China airports to 63 SA\&SEA airports, and ATN travel time of any pair of airports could be easily determined.

$$
\begin{gathered}
t_{\text {direct }_{f r}}, t_{\text {non }_{f r}}=\frac{\sum_{\text {time }_{f r}}}{N_{f r}} \\
t_{A P 1_{-} A P 2}=\min \left(t_{\text {direct_f }_{-} r}, t_{\text {non } f r}\right)
\end{gathered}
$$

where time $_{f r}$ is the travel time of a single trip for different flight routes and $N_{f r}$ is the total number of flights during 60-day period. $t_{\text {direct_f } r}$ and $t_{n o n_{-} f r}$ are the daily average travel time for direct and non-direct flight routes, respectively, and $t_{A P 1 \_A P 2}$ is the ATN travel time between $A P 1$ and $A P 2$.

(3) Minimum total travel time. Due to the extension of international airline options, travelers have more choice in terms of different departure and arrival airports. In this study, we assumed that airports with the least total travel time were the target connection airports for given residential areas. The total travel time contained three parts: travel time from China residential area $i$ to China airport $A P 1\left(t_{i \_A P 1}\right)$, travel time from $A P 1$ to SA\&SEA airport $A P 2\left(t_{A P 1 \_A P 2}\right)$, and travel time from $A P 2$ to SA\&SEA residential area $j\left(t_{A P 2_{-} j}\right)$. The minimum value of the sum of these three values $\left(t_{i_{-} A P 1}+t_{A P 1_{-} \mathrm{AP2}}+t_{A P 2_{-} j}\right)$ was set as the point-to-point minimum total travel time between $i$ and $j\left(t_{i j}\right)$ (Figure $3 \mathrm{~A}$ ).

\subsection{Temporal-Range Radiation Model for Travel Probability}

\subsubsection{Description of the Temporal-Range Radiation Model}

The radiation model, which simulates particle movement, was proposed to measure the travel probability [32]. The modified temporal-range radiation model assumes that when an individual travels from origin point to destination point, he/she has a larger probability of being absorbed by temporally adjacent areas (temporal range) with greater populations than by other areas [38]. Thus, the travel probability is negatively correlated with total population within a certain temporal range between given origin and destination points $[38,40]$.

In this study, the origin point was set as China residential area $i$, with population of pop $_{i}$, and the destination point was set as SA\&SEA residential area $j$, with population of $p_{p} p_{j}$. The temporal range between $i$ and $j$ were the set of the potential residential areas $m$, where minimum travel time from $i$ to SA\&SEA residential areas $m\left(t_{i m}\right)$ was less than minimum travel time from $i$ to $j\left(t_{i j}\right)$, which could be calculated based on Section 3.1. In contrast to the circle region of spatial range, the temporal range was irregularly shaped, and only related with travel time (Figure 3B). For each pair of China and SA\&SEA residential 
points, the point-to-point travel probability from $i$ to $j\left(p_{i j}\right)$ by the radiation model within a certain temporal range $S$ was calculated as Equation (2):

$$
\begin{aligned}
& p_{i j}=\frac{\text { op }_{i} \times p o p_{j}}{\left(\text { pop }_{i}+\text { Pop }_{S}\right) \times\left(\text { pop }_{i}+\text { pop }_{j}+\text { Pop }_{S}\right)} \\
& \text { Pop }_{S}=\sum \text { pop }_{m}, m \in\left\{t_{i m}<=t_{i j}, m \neq j\right\}
\end{aligned}
$$

where $p_{i j}$ is the travel probability from residential area $i$ to $j, p o p_{i}$ and $p o p_{j}$ are the population of $i$ and $j$, respectively. $P o p_{S}$ is the population sum for temporal region $S$, containing potential residential areas $m . t_{i j}$ and $t_{i m}$ are the minimum total travel time from $i$ to $j$ and from $i$ to $m$, respectively.

\section{(A) Minimum total travel time}

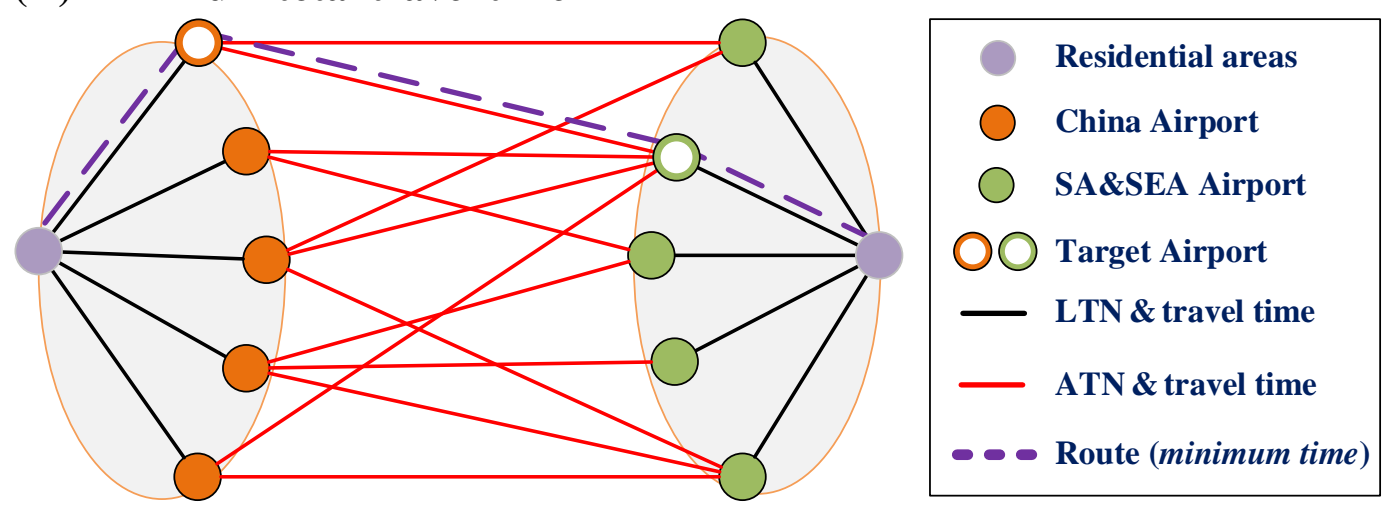

(B) Temporal \& spatial range

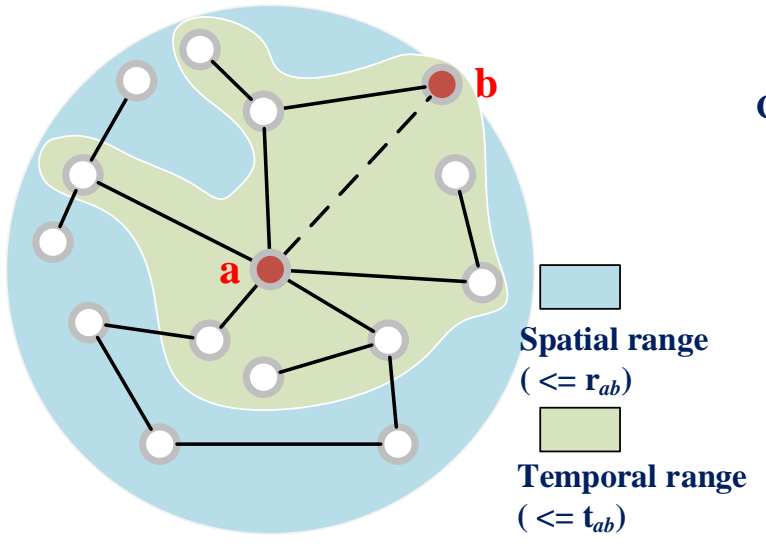

(C) Subregions for temporal range

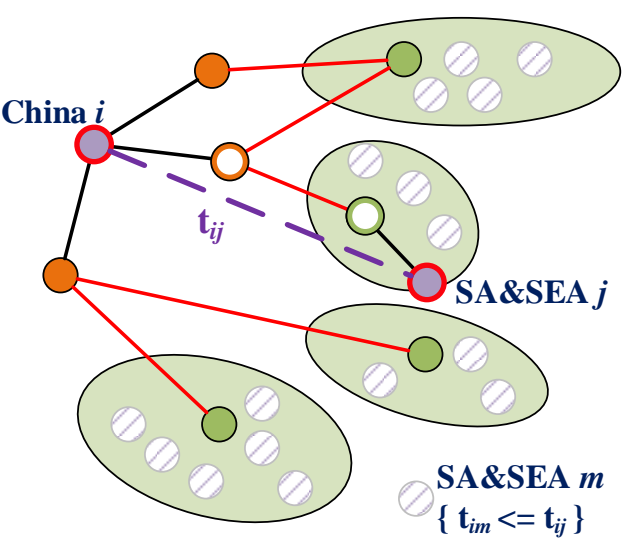

Figure 3. The sketch map of (A) minimum total travel time between residential areas, (B) differences between temporal range and spatial range for the radiation model, (C) subregions for the temporal range between China residential area $i$ and SA\&SEA residential area $j$.

\subsubsection{Identification of Temporal Range}

According to Equation (2), the calculation of $P o p_{s}$ and identification of temporal range $S$ were the core of the temporal-range radiation model, where $p o p_{i}$ and $p o p_{j}$ were specific. The existing temporal or spatial range for radiation model was the spatially continuous region around origin $i$ [32] (Figure 3B). However, transnational travel natively separated the origin $i$ and destination $j$. In addition, the target destination was the SA\&SEA country instead of China, and any regions in China should not be considered for temporal range. Thus, the origin $i$ and temporal range $S$ were disconnected, and $S$ should be in the same country as $j$ (Figure 3C).

Moreover, for countries with one destination airport, such as Singapore and Nepal, the temporal range was unique. For countries with multiple airports, with the exception of 
target SA\&SEA airport AP2, regions around other airports could include some residential areas with minimum total travel time $t_{i m}$ less than $t_{i j}$. Notably, transnational LTNs were not considered in this study, and these regions were in the same country as $j$. This means that residential area $m$ might be spatially detached from residential area $j$, resulting in several independent subregions of temporal range $S$ around different airports within the same country (Figure 3C). Different subregions had various sizes, different numbers of residential areas, and different target destination airports within the same country. By comparison, the origin airport in China could be the same for residential area $m$ in different subregions. At the intersections of these subregions, the population was counted only once and $\mathrm{Pop}_{s}$ was the summed population of these subregions.

\subsection{Weighted-Average Model for National Scale Accessibility}

After obtaining travel probability between different pairs of residential areas, the weighted-average model was introduced to integrate the travel time and travel probability at the national scale. In this study, 44,682 residential points in China and 72,916 residential points in SA\&SEA were considered, resulting in $44,682 \times 72,916$ pairs of travel probability. For travel time, lookup tables were constructed from each residential area to a maximum of 5 potential airports and each pair of airports. For each travel probability, the corresponding minimum total travel time could be easily queried from these tables. Then the national scale accessibility was calculated from each residential area in China to all residential areas within each SA\&SEA country based on the weighted-average model, with the travel probability as the integrated weight (Equation (3)). This national scale accessibility represented the weighted-average travel time to each SA\&SEA country for each residential area in China.

$$
T_{i}^{k}=\frac{\sum_{j=1}^{n} t_{i j} \times p_{i j}}{\sum_{j=1}^{k-n} p_{i j}}
$$

where $T_{i}^{k}$ is the weighted-average travel time from China residential area $i$ to all residential areas in SA\&SEA country $k, t_{i j}$ and $p_{i j}$ are the point-to-point travel time and travel probability, respectively, and $n$ is the number of residential areas in country $k$.

The above-mentioned processes were mainly conducted using Python 3.6 and related libraries, with the help of ArcMap 10.2.

\section{Results}

\subsection{Travel Time from Web-Sourced Datasets}

(1) Travel time in air transport networks

Approximately 417 direct flight routes (airlines) were offered from 53 China airports to 48 SA\&SEA airports, where the average number of daily flights was about 809 and the average flight time was about $4.21 \mathrm{~h}$ (Table 2). Direct flight routes were mainly concentrated in the southeast, east, and southwest regions of China (Figure 4A), and airports in Hong Kong, Guangzhou, Taipei, Shanghai, Beijing, and Kunming city (IATA codes: HKG, CAN, TPE, SHA/PVG, PEK/NAY, and KMG) had the largest number of daily direct flights to SA\&SEA. These regions or cities are advantageously positioned relative to SA\&SEA, and most cities offer more than three daily direct flights on average (Figure 4A).

Overall, 3776 non-direct flight routes were identified, representing an average of 71,034 daily flights with an average flight time of $19.62 \mathrm{~h}$ (Table 2). In addition, the overall flight time for non-direct flights included layover time, resulting in a value that was far larger than that of direct routes. For non-direct routes, the average number of layovers showed a positive relationship with total flight time. Moreover, most of the non-direct flights had an average of 1.00 to 1.86 layovers, also accounting for a large proportion of daily flights. 
Table 2. Direct and non-direct flight route information, including daily average number of routes, daily average number of flights, average flight time (FT), and the involved number of China airports (AP) and SA\&SEA airports (including two airports (IATA codes) with the largest total number of flights). The non-direct flights were divided into four categories according to the average number of flight routes, with a different number of layovers (1)-(4).

\begin{tabular}{cccccc}
\hline & Routes & Flights & FT (hours) & China AP & SA\&SEA AP \\
\hline Direct & 417 & 809 & 4.21 & 53-HKG/CAN & 48-BKK/SIN \\
\hline Non-direct & 3776 & 71,034 & 19.62 & 65-HKG/TPE & 63-BKK/HKT \\
\hline (1) $1.00-1.64$ & 968 & 29,493 & 17.25 & 62-SHA/HKG & 46-BKK/SIN \\
\hline (2) $1.65-1.86$ & 988 & 20,256 & 17.09 & 63-TPE/HKG & 61-KBV /CEI \\
\hline (3) $1.87-1.98$ & 986 & 15,919 & 24.98 & 62-TPE/CGQ & 57-URT/UTH \\
\hline (4) $>1.99$ & 834 & 5366 & 26.22 & 57-WNZ/LHW & 57-BLR/HUI \\
\hline
\end{tabular}
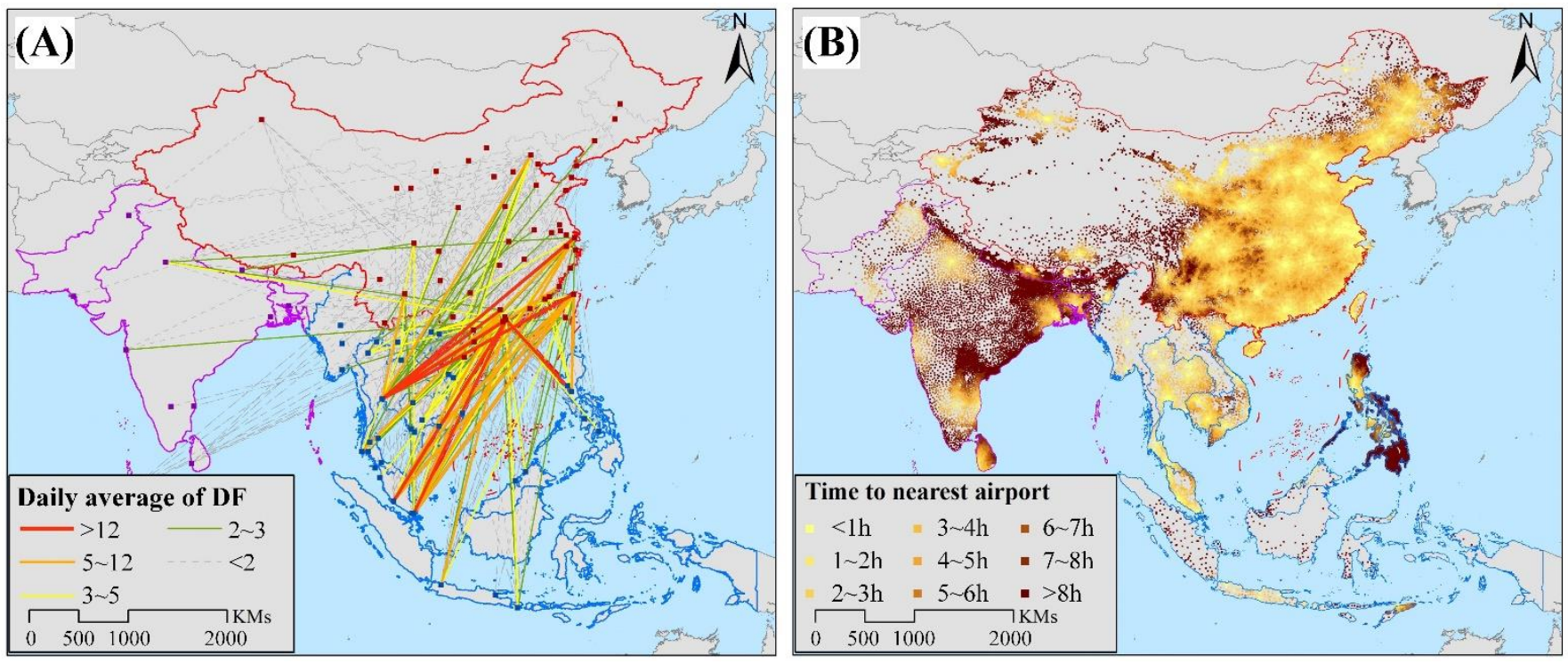

Figure 4. (A) The daily average number of direct flights (DF) from China airports to SA\&SEA airports. (B) The travel time in land transport networks from each residential point to the nearest airport within each country. The figure is under the WGS-84 geographical coordinate system.

(2) Travel time in land transport networks

LTN travel time was calculated based on the least travel time from residential points to target airports according to Baidu Maps and Google Maps API. Figure 4B showed travel time to the nearest airport for each residential point, with a clearly visible radial spatial pattern around airports. For economically developed regions in eastern China, travel time to the airports was much smaller due to dense airports and highly developed LTNs. The statistics data suggested that about $89.10 \%$ of China's population can travel to the nearest airport under $4 \mathrm{~h}$ via public transit or driving. In most SEA countries, the majority of the population could reach the nearest airport within 2-4 h (Figure $4 \mathrm{~B}$ ). This may be attributable to two main factors: (1) some SEA countries, such as Singapore and Brunei, have a relatively small area, and (2) some countries have several navigable airports with links to China, such as Thailand and Malaysia (Table 1). In SA, most of the population had a higher travel time to the nearest navigable airport, due to the relative dearth of international airports, poor LTNs, or more widely dispersed residential areas. 


\subsection{Travel Probability by Temporal-Range Radiation Model}

Travel probability was calculated using the temporal-range radiation model for each residential area in China. For easier interpretation, county-scale summaries for travel probability were prepared. Administrative data were acquired from the Global Administrative Areas dataset (GADM, http:/ / gadm.org/, accessed on 10 May 2018) for the 2456 county administrative units in China. Then, the average travel probability was calculated between these areas and 10 countries in SEA (Figure 5A) and eight countries in SA (Figure 5B). Overall, China had higher levels of travel probability with SEA than with SA, especially in central and west China, such as Sichuan, Chongqing, and Hubei provinces. However, counties in north and northwest China region had higher levels of travel probability with SA region, such as Shandong and Xinjiang provinces. Regarding the spatial distribution of travel probability in China, counties around major cities had the highest probability of traveling to SA\&SEA. East and southeast China had the highest overall travel probability, including Shanghai, Jiangsu, Zhejiang, Guangdong, and Fujian provinces. In west China, counties within or around Kunming, Chengdu, Chongqing, and Xi'an cities had high travel probability. Counties in the northeast and northwest regions had relatively lower travel probability with SA\&SEA.
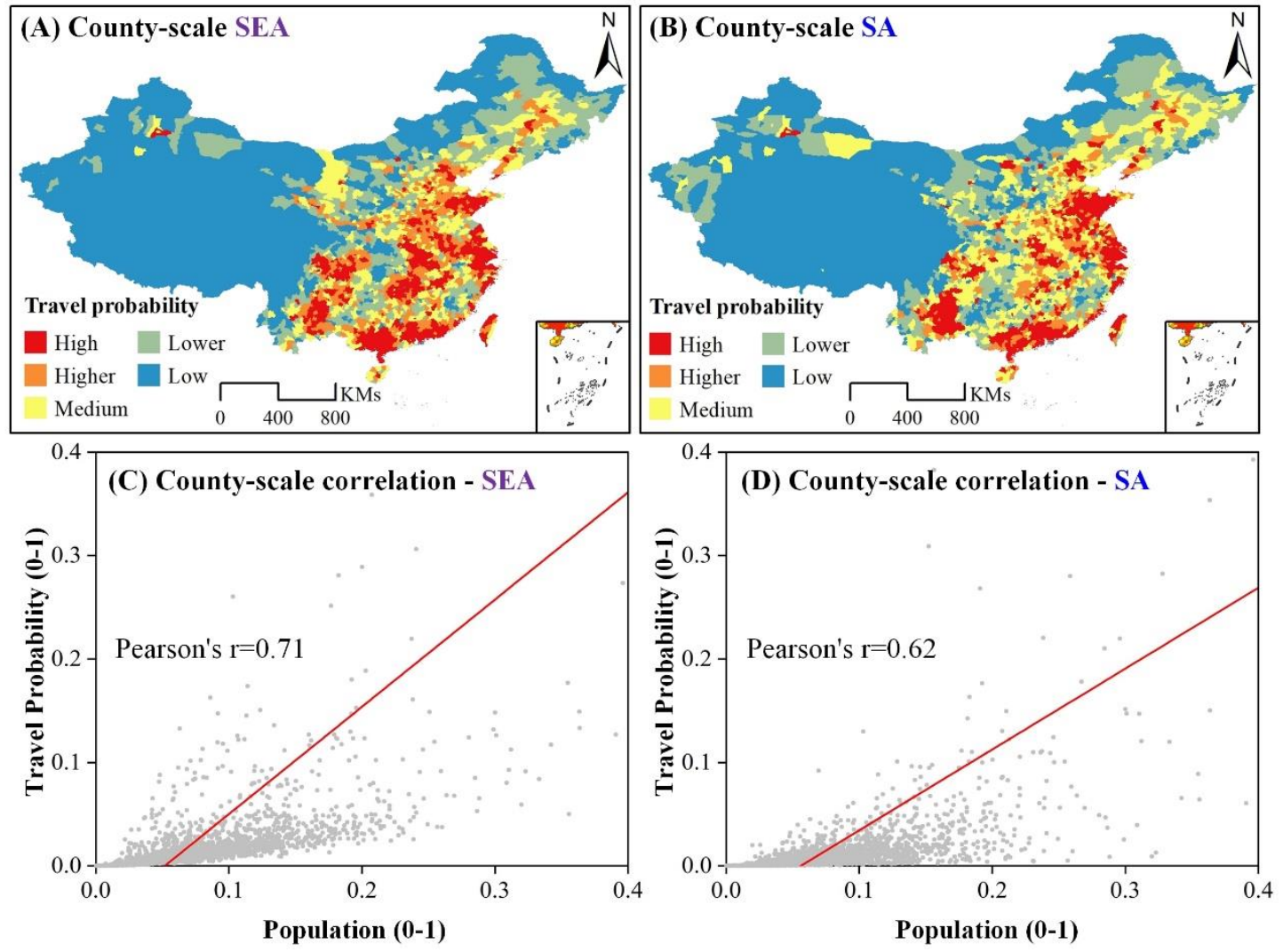

Figure 5. County scale travel probability from China to SEA (A) and SA (B); County scale correlation between population and travel probability for SEA (C) and SA (D); travel probability and population are normalized to $0-1$ and data in $0.6-1$ are hidden due to poor data quantity. The figure is under the WGS-84 geographical coordinate system.

\subsection{Accessibility at National Scale}

The overall accessibility of each country was based on the travel probability and travel time between different residential points. The results revealed that China has higher general accessibility to SEA countries than SA countries, with smaller weighted-average travel time (Figure 6). Overall, residential areas near Beijing had relatively higher accessibility to each country, reflecting Beijing's important political role, and Hong Kong, Macao, and 
Taiwan experienced higher general accessibility to most countries due to their earlier and stronger international connections.
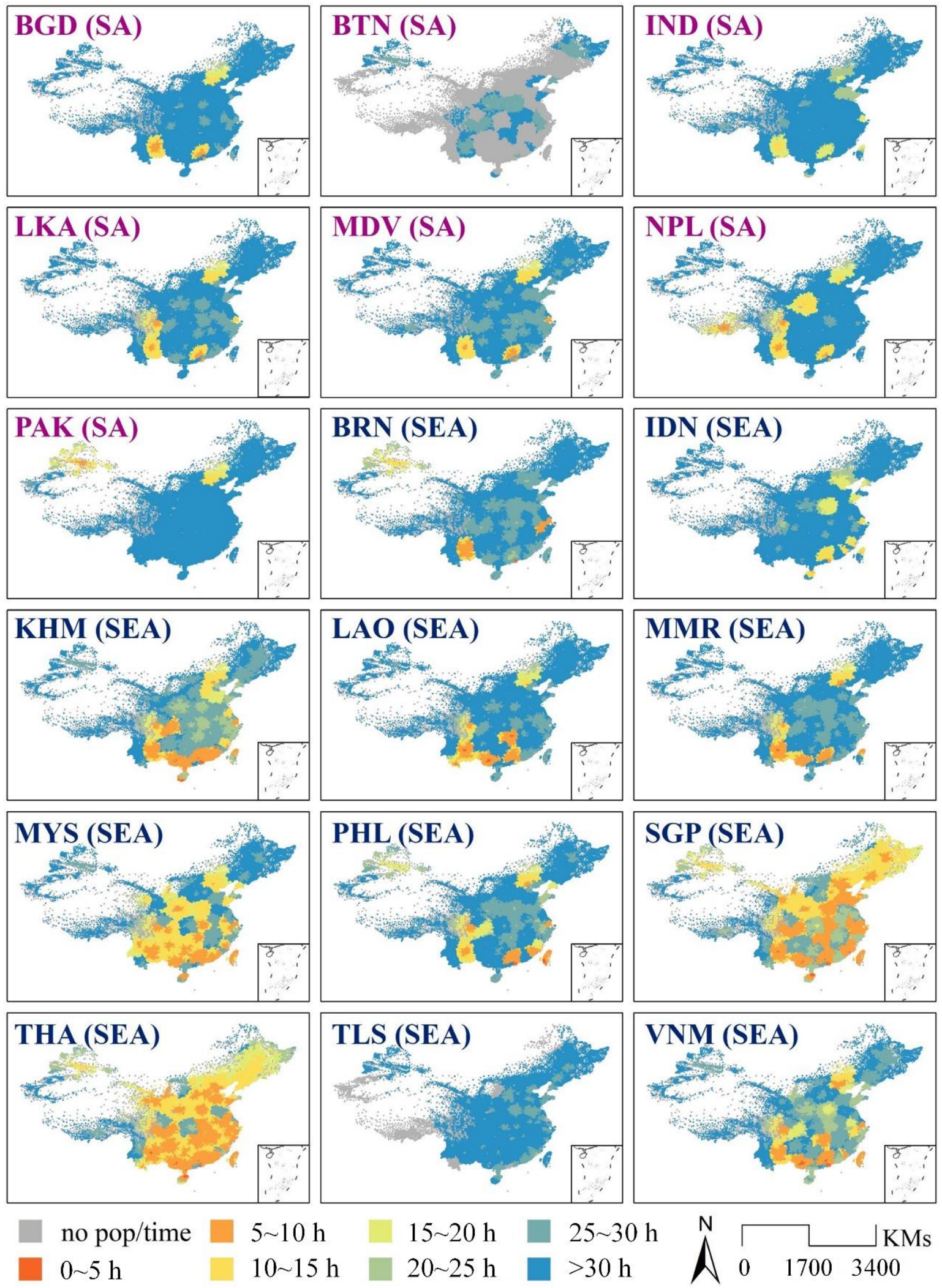

Figure 6. The weighted-average travel time from 44,682 China residential areas to each SA\&SEA country. The figure is under the WGS-84 geographical coordinate system. 
Most residential areas in China had relatively high accessibility to Sri Lanka, Maldives, and Nepal in SA, because these countries are popular tourist destinations. Bhutan, India, and Pakistan were less accessible from China (Figure 6). Regions with high accessibility to SA countries were concentrated in southwest and south China, such as Yunnan, Chongqing, and Guangdong provinces (Figure 6). Xinjiang and Xizang provinces had the highest accessibility to Pakistan and Nepal, respectively, due to their geographical proximity. For SEA, most regions in China had high accessibility to Thailand, Singapore, and Malaysia, but relatively low general accessibility to Timor-Leste, Indonesia, and Brunei. High accessibility regions in China were concentrated in the southwest, south, and east regions, such as Yunnan, Hainan, Guangxi, Guangdong, and Fujian provinces.

The population cumulative curve on weighted-average travel time increased more gently in SEA than in SA, where a sharp increase indicated the travel time range of population concentration (Figure 7). This range for the SA region was about $25-40 \mathrm{~h}$, whereas the range for the SEA region was only about $10-25 \mathrm{~h}$, indicating a better accessibility situation in the SEA region. About $85 \%$ of China's population can travel to Thailand and Singapore within an average travel time of $16 \mathrm{~h}$ and $22 \mathrm{~h}$, respectively. For Cambodia, Vietnam, and Malaysia, these values increased to 28,30 , and $30.2 \mathrm{~h}$ respectively, indicating slightly poorer accessibility. This value increased considerably to about $34 \mathrm{~h}$ for other SEA countries and to around $40 \mathrm{~h}$ for other SA countries.

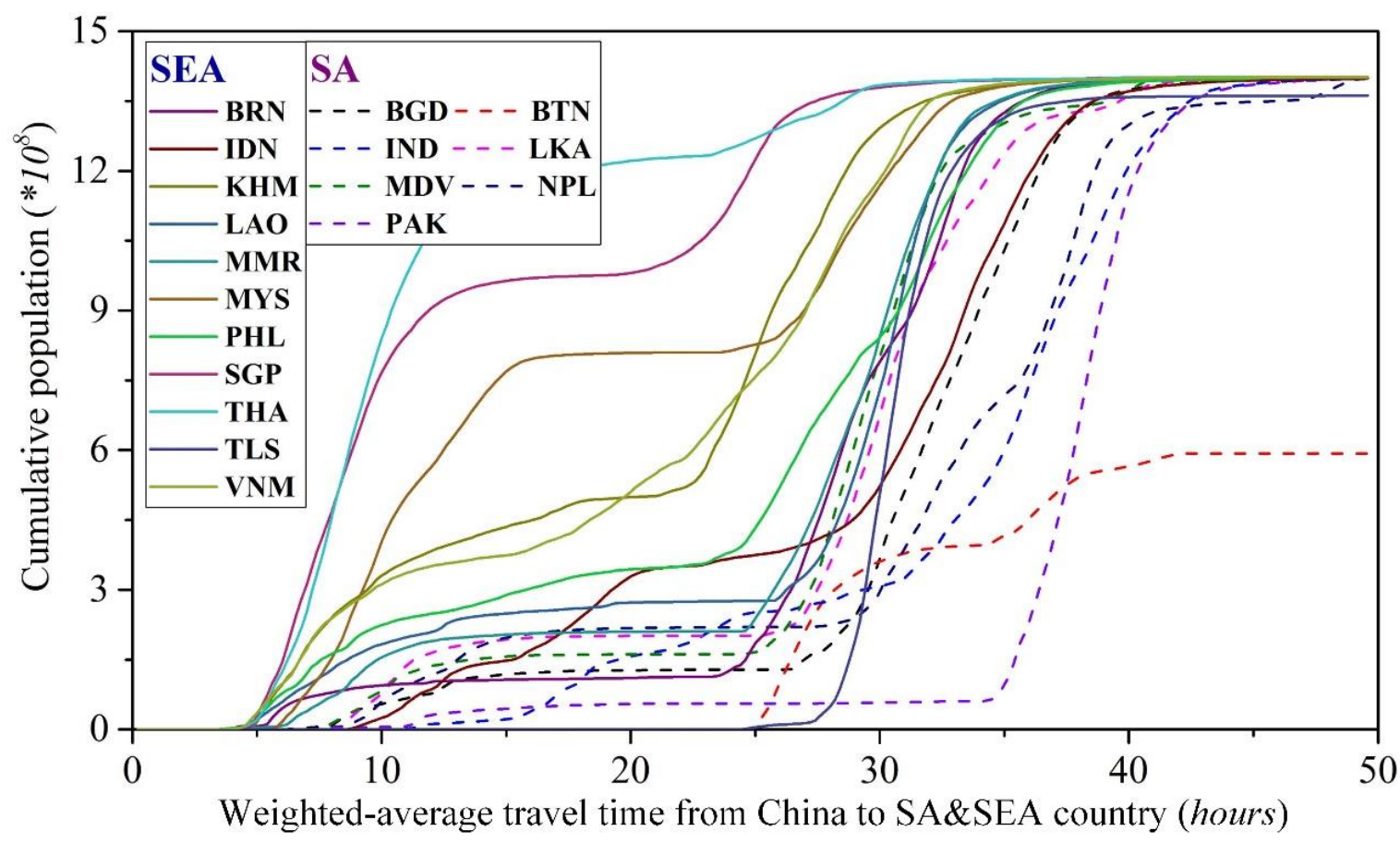

Figure 7. Cumulative population curve on weighted-average travel time from China to each SA\&SEA country.

\section{Discussion}

\subsection{Airport Selection and Web-Sourced Data}

High level of transport accessibility is the cornerstone of the B\&R's goal to promote political, economic, and cultural collaborations between China and SA\&SEA. Air travel is a vital transport mode for international and large-scale movement of people and goods $[47,48]$. The number of global aviation passengers reached 3.79 billion in 2016, representing an increase of about $54 \%$ over the previous 10 years. The Asia-Pacific region contributed most to this increase, accounting for 32.9\% [49]. As supplements of ATNs, LTNs are also essential for transnational travel and serve as important connections between residential areas and airports. Because airports serve as ATN/LTN connection nodes, airport choice may greatly influence the overall travel time and inter-regional accessibility results. The 
various influencing factors associated with airport choice, including price, travel cost, and travel mode, make evaluations of airport choice complex [17,50-52]. Travel time was the only factor considered to affect airport selection in this study, and should be the most important factor. Meanwhile, travel time was also the only uncertain variable for the construction of the temporal-range for the radiation model, which organically related these two indicators. In future studies, more influencing factors should be considered for airport choice to yield more accurate travel time estimates.

In this study, travel time between residential areas was acquired from online platforms, allowing calculation without the need to construct the physical multimodal transport networks [53,54]. Moreover, ATNs exert a larger influence on overall accessibility for flight time is much larger than LTN travel time, and thus determining accurate ATN travel time is particularly important. Unlike statistical airline data, online booking platforms provide the average flight time from actual daily flight arrangements, and time series data can be constructed for further analysis. Similarly, LTN travel time was also acquired from web mapping APIs, thereby avoiding repeated works for road network analysis. In addition, current web mapping services contain accurate geographical data that are not easily obtained through other methods, making such platforms suitable for use in scientific research.

\subsection{Temporal-Range Radiation Model and Simple Validation}

Travel population and travel probability are metrics that quantify potential opportunity for interaction, and it is important to integrate the travel time between residential areas when considering these metrics. However, multimodal transport networks are characterized by a wide variety of travel population flow, making it difficult to estimate travel populations. New techniques, such as deep learning and big data, can provide more precise estimates of the travel population, but these methods are greatly limited by the original data [55]. Thus, the spatial interaction model is still the preferred method for estimating the large-scale or transnational travel probability/population by considering spatial correlations of different population units [56]. In this study, the temporal-range radiation model was used to estimate travel probability, with population point data as the model input. Population grid datasets have relatively finer spatial granularity, but large amounts of grid data are null values without population numbers $[57,58]$. Meanwhile, the use of grid datasets entails a relatively high computation time, where the computation complexity of the radiation model is about $\mathrm{O}\left(\mathrm{n}^{2}\right)$. Thus, population datasets of county units were selected for their balance between accuracy and computation efficiency.

Moreover, in contrast to the original spatial-range model, travel time was set as the criterion for temporal range $S$ in our radiation model [38]. Region $S$ for a single LTN or ATN was defined as the unique spatially continuous area around origin residential areas. In multimodal transport processes, airport selection can result in non-contiguous temporal ranges with a center of different SA\&SEA airports. Within a given country, large airports with more direct flight routes have a more complete LTN and larger surrounding population than smaller airports (Figure 4B). Thus, for a certain destination residential point, subregions of $S$ around other small airports may cover less population, and subregions of $S$ around other large airports may cover larger population. Consequently, populated areas are essentially guaranteed to have a higher travel probability in the radiation model, and also have a greater accessibility weight. This outcome is in agreement with existing research that identified a high correlation between population and accessibility levels $[59,60]$, which qualitatively supports the reliability of the radiation model for accessibility research.

We also determined the county scale correlation between population and travel probability, where Pearson's r (correlation coefficient) was 0.71 and 0.62 for SEA and SA, respectively (Figure 5C,D). This indicates that regions with a larger population have a larger travel probability, which also aligns with existing research [32,37]. For the validation of transnational travel probability, datasets with actual values are often hard to obtain. This study considered validation data from the " 2019 big data report on outbound tourism for 
the B\&R" [61], which ranks the number of passengers from different Chinese cities that travel to various SEA countries. This kind of travel population ranking was comparable to our estimated travel probability, and city-scale travel probability was also summed based on GADM data. The city-level rankings were more consistent with the estimation results of the temporal-range radiation model, both for Thailand and Indonesia (Figure 8A,B). However, the estimation results using the spatial-range radiation model and gravity model had some large outliers, such as Shenzhen and Guangzhou cities, and small outliers, such as Ha'erbin and Wuhan cities. In addition, these three models also overestimated the travel probability of some cities that were not within the top 20 in the report, including three cities in the temporal-range radiation model, nine in the spatial-range radiation model, and 12 in the gravity model. These results further indicate that the temporal-range radiation model offers better performance in delineating the spatial distribution of transnational travel probability.
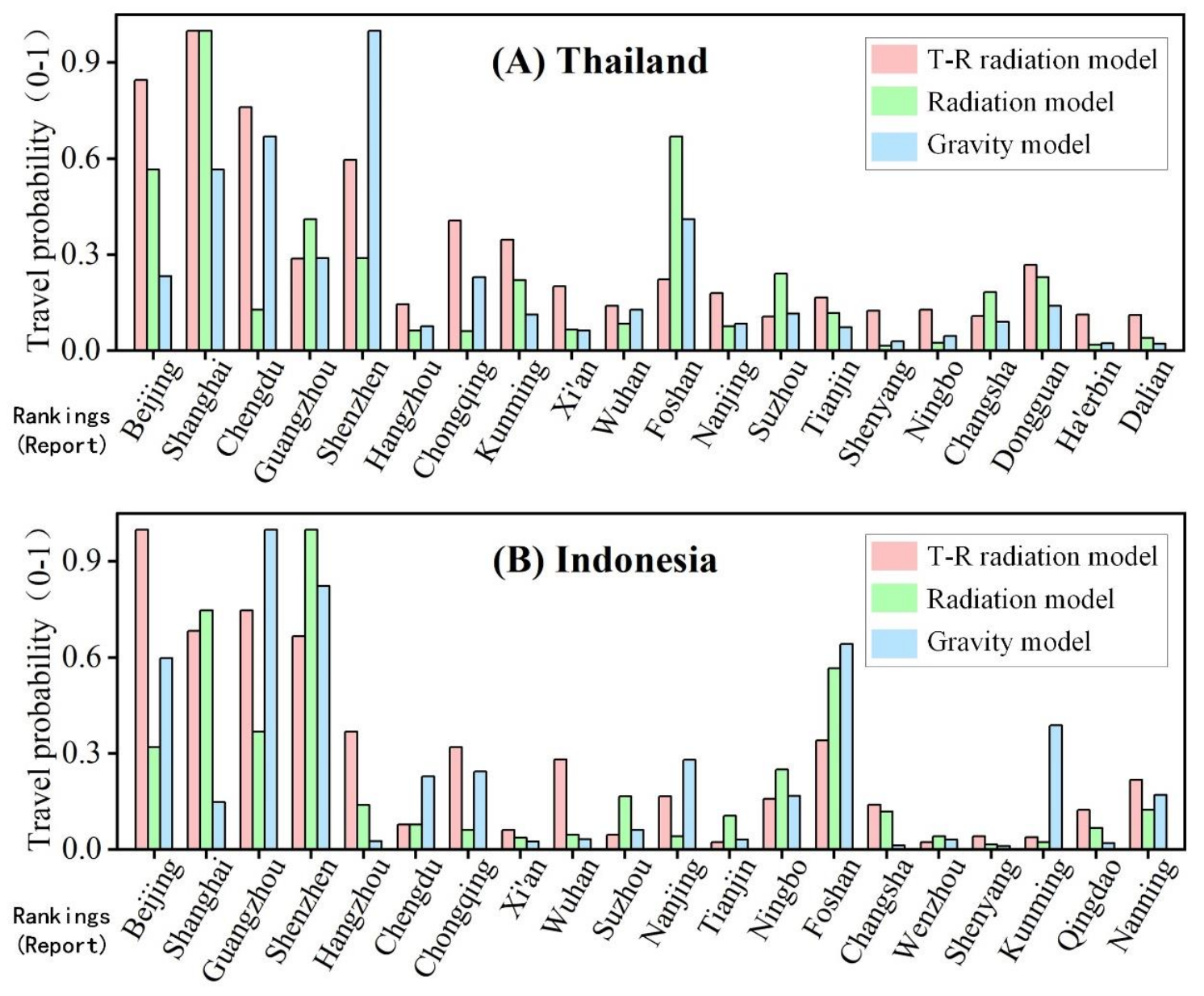

Figure 8. Travel probability estimation results by temporal-range (T-R) radiation model, radiation model (spatial-range), and gravity model from China to (A) Thailand and (B) Indonesia. Top 20 cities and rankings on the $x$-axis are from the "2019 big data report on outbound tourism".

\subsection{Overall Accessibility and Analysis}

Generally speaking, SA\&SEA countries have high overall accessibility to China, and particularly the SEA region. However, because no directly related research or authentication datasets exist, the validation or comparison of the accessibility levels calculated in this study is difficult, and only the general rationality of our results could be verified. According to statistical data, the 10 most popular international travel destinations for Chinese tourists includes seven countries and four cities in SA\&SEA, with $20 \%$ of the tourist population selecting Thailand in 2017 [62]. Of the 10 most popular islands for vacations, eight are 
located in this region, including Phuket/Samui/Krabi in Thailand, Sabah in Malaysia, Nha Trang in Vietnam, Boracay in Philippines, Maldives, and Bali in Indonesia. In addition, China has proactively and rapidly improved its ATN and strengthened transnational air travel to surrounding areas, especially SA\&SEA [63,64]. All of this evidence illustrates the strong existing relationship between China and SA\&SEA, and suggests a high level of inter-regional accessibility.

Based on the parameters of the assessment index, high overall accessibility can be attributed to lower travel time and higher travel probability. Travel time in LTNs entailed relatively minor spatial differences, where travel time for most regions was less than $4 \mathrm{~h}$ and ranges were rarely larger than $4 \mathrm{~h}$. For ATNs, flight time for direct and non-direct airlines had more significant spatial differences, where the variation of average time was about $15 \mathrm{~h}$ (Table 2). Thus, more direct flights and greater airport connectivity could greatly decrease the travel time and increase the overall accessibility, such as to Thailand, Singapore, and Malaysia in SEA. Analysis of the daily average flights also showed that the economically developed regions or capital cities had larger numbers of transnational flights.

In addition, some SA\&SEA countries have deep-rooted connections and an enormous demand for direct flights to southeast China, where ethnic Chinese accounted for about $74.1 \%, 21 \%$, and $16 \%$ of the populations of Singapore, Malaysia, and Thailand in 2010. In Vietnam, the number of Chinese travelers reached 4 million in 2018, representing 30\% of total inbound tourists. As the popular tourist destinations, these SEA countries, in addition to Sri Lanka, Maldives, and Nepal in SA, have high numbers of direct airlines from China [61,62]. Regarding travel probability, denser population distributions may result in larger probability values based on the strong linear correlation and the properties of temporal-range radiation model. However, travel probability is also greatly influenced by the travel time or the availability of direct flights. For example, Jiangsu and Zhejiang provinces have similar geographical locations, although Jiangsu has a higher population and more international airports. However, Jiangsu's six airports offer only 13 direct flight routes to SA\&SEA, and the Hangzhou airport in Zhejiang offers nearly the same number. The additional 10 direct routes from Ningbo and Wenzhou give Zhejiang a higher overall accessibility level than Jiangsu.

\subsection{Suggestions to Improve Accessibility}

Because transit nodes connect LTNs and transnational ATNs, international airports should be the main focus of initiatives to improve accessibility [65]. When jointly analyzing the population coverage of LTNs and number of flights in ATNs (navigable capacity) for different airports, clear differences emerge among China airports (Figure 9A,B). In direct ATNs, some airports that offer high connectivity to many international destinations are situated within LTNs that serve huge populations, including airports in Guangzhou, Beijing, Kunming, Chengdu, Shenzhen, and Shanghai cities (IATA codes: CAN, BJS, KMG, CTU, SZX, and SHA). These airports are located in major regional cities with complete public transit networks that allow the surrounding population to reach airports quickly. In non-direct ATNs, airports in Beijing and Shenyang city (IATA code: SHE) are examples of the above-mentioned nodes (Figure 9B). These airports are the key nodes connecting China and SA\&SEA, and issues within the international transit network would arise if problems occurred at these nodes. Therefore, the construction of complementary airports in these cities, such as Chengdu and Kunming city, could help improve the robustness of ATNs. 

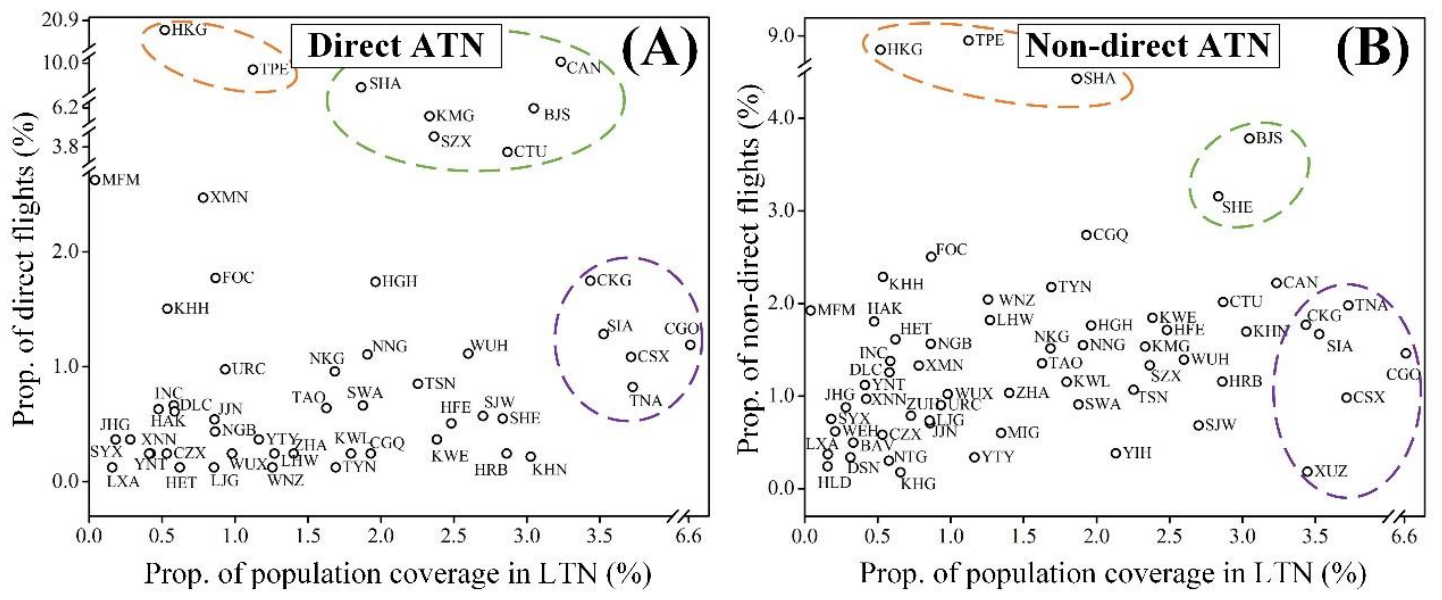

Figure 9. The relationship between proportion (prop.) of population to the nearest airport in LTN and the proportion of direct flights (A) and non-direct flights (B) to SA\&SEA.

In addition, some airports have a high daily average number of direct or non-direct flights, but are situated within LTNs with relatively low population coverage, including airports in Xiamen, Fuzhou, and Haikou cities (IATA codes: XMN, FOC, HAK) (Figure 9A). These airports offer several travel options to SA\&SEA but their LTNs have relatively low transport capacities. For example, Fuzhou and Xiamen cities, both in Fujian Province, had only two high-speed railways in 2017, making it difficult to take advantage of their well-developed ATNs. Therefore, to improve overall accessibility, the LTN infrastructure supporting these airports should be expanded, such as railways and highways. Moreover, other airports have the ability to draw large populations via LTNs, but offer only a small number of routes or flights to SA\&SEA, such as airports in Chongqing, $\mathrm{Xi}^{\prime}$ an, Zhengzhou, Changsha, Ji'nan, and Xuzhou cities (IATA codes: CKG, SIA, CGO, CSX, TNA, SUZ). These airports are mostly located in west and central China, and are the only international airport available for large, densely populated regions. Therefore, to improve the overall accessibility, the daily number of flights should be increased, and available routes should be expanded at existing airports or new airports could be constructed. Furthermore, increasing domestic connections at these airports could also improve overall accessibility.

\section{Conclusions}

Transnational accessibility between China and SA\&SEA regions via ATNs and LTNs is an essential component of the $B \& R$. However, transnational travel processes involve a multimodal transport system, creating a problem for the construction of accessibility indices, including data acquisition for travel time and model adaption for travel probability. In this study, transnational travel time was acquired from various online platforms, and travel probability was calculated using the temporal-range radiation model. Then, the overall accessibility was set as the weighted-average travel time from each China residential area to each SA\&SEA country. The results showed that China had better accessibility to SEA than SA, because the weighted-average travel time to SA was about $25-40 \mathrm{~h}$ and that to SEA was only about $10-25 \mathrm{~h}$. The countries with best overall accessibility were Thailand, Singapore, and Malaysia in SEA, and Sri Lanka, Maldives, and Nepal in SA. Southwest, south, and southeast China had greater access to SA\&SEA than other regions of China. Based on conjoint analysis, improving LTNs around airports with low population coverage and increasing direct routes/flights of airports with low navigable capacity are suggested to improve overall accessibility. Our study introduced multiple online platforms to calculate the travel time under the multimodal transport system, and solved the problem of the identification of the temporal range of the radiation model for transnational processes. Furthermore, fine-scale accessibility results between China and SA\&SEA could also help to guide the improvements. 
However, the proposed framework and results leave room for further refinement and research. First, the waiting time between the LTN and ATN was not considered, and further study will consider this for more accurate estimation. In addition, time series analysis of flight information and spatial patterns of overall accessibility also need in-depth study. Second, to improve the reliability of transnational travel probability/population estimates, more comprehensive parameters should be considered within more sophisticated models. Finally, the lack of quantitative validation for transnational travel probability and overall accessibility should be addressed through the excavation of more reliable datasets. Moreover, the COVID-19 pandemic has already changed the current situation, and future work will focus more on the transport accessibility and change analysis before and after the pandemic.

Author Contributions: Conceptualization, Nan Xia; methodology, Liang Cheng; formal analysis, Nan Xia; writing_original draft, Nan Xia and Manchun Li; writing_review and editing, Liang Cheng; visualization, Nan Xia and Manchun Li; supervision, Manchun Li; project administration, Manchun Li All authors have read and agreed to the published version of the manuscript.

Funding: This research was funded the National Key Research and Development Program of China (2017YFB0504205), comments and contributions of anonymous reviewers and members of the editorial team. The National Natural Science Foundation of China (41622109), and China postdoctoral Science foundation (2020M681545). Sincere thanks are given for the comments and contributions of anonymous reviewers and members of the editorial team.

Institutional Review Board Statement: Not applicable.

Informed Consent Statement: Not applicable.

Data Availability Statement: The data presented in this study are available on request from the corresponding author. The data are not publicly available due to privacy.

Conflicts of Interest: The authors declare no conflict of interest.

\section{References}

1. Laurance, W.F.; Clements, G.R.; Sloan, S.; O'connell, C.S.; Mueller, N.D.; Goosem, M.; Venter, O.; Edwards, D.P.; Phalan, B.; Balmford, A.; et al. A global strategy for road building. Nature 2014, 513, 229-232. [CrossRef] [PubMed]

2. Jia, H.P.; Guo, H.D. Scientific collaborations shine on Belt and Road. Natl. Sci. Rev. 2017, 4, 652-657. [CrossRef]

3. Weidong, L.; Zhouying, S.; Zhigao, L. Progress in research on the Belt and Road Initiative. Acta Geogr. Sin. 2018, 73, 620-636. (In Chinese)

4. Verburg, P.H.; Ellis, E.C.; Letourneau, A. A global assessment of market accessibility and market influence for global environmental change studies. Environ. Res. Lett. 2011, 6, 034019. [CrossRef]

5. Graham, A. Air transport in the Asia Pacific. Tour. Manag. 2016, 54, 150-151. [CrossRef]

6. Dalvi, M.Q.; Martin, K.M. Measurement of Accessibility-Some Preliminary Results. Transportation 1976, 5, 17-42. [CrossRef]

7. Geurs, K.T.; van Wee, B. Accessibility evaluation of land-use and transport strategies: Review and research directions. J. Transp. Geogr. 2004, 12, 127-140. [CrossRef]

8. Bao, D.W.; Hua, S.Y.; Gu, J.Y. Relevance of airport accessibility and airport competition. J. Air Transp. Manag. 2016, 55, 52-60. [CrossRef]

9. Di Ciommo, F.; Shiftan, Y. Transport equity analysis. Transp. Rev. 2017, 37, 139-151. [CrossRef]

10. Matisziw, T.C.; Grubesic, T.H. Evaluating locational accessibility to the US air transportation system. Transp. Res. Part A Policy Pract. 2010, 44, 710-722. [CrossRef]

11. Huang, Z.; Wu, X.; Garcia, A.J.; Fik, T.J.; Tatem, A.J. An Open-Access Modeled Passenger Flow Matrix for the Global Air Network in 2010. PLoS ONE 2013, 8, e64317. [CrossRef] [PubMed]

12. Mao, L.; Wu, X.; Huang, Z.J.; Tatem, A.J. Modeling monthly flows of global air travel passengers: An open-access data resource. J. Transp. Geogr. 2015, 48, 52-60. [CrossRef] [PubMed]

13. Thill, J.C.; Lim, H. Intermodal containerized shipping in foreign trade and regional accessibility advantages. J. Transp. Geogr. 2010, 18, 530-547. [CrossRef]

14. Jiang, C.M.; Zhang, A.M. Effects of high-speed rail and airline cooperation under hub airport capacity constraint. Transp. Res. Part B Methodol. 2014, 60, 33-49. [CrossRef]

15. Roman, C.; Martin, J.C. Integration of HSR and air transport: Understanding passengers' preferences. Transp. Res. Part E Logist. Transp. Rev. 2014, 71, 129-141. [CrossRef] 
16. Vega, A.; Reynolds-Feighan, A. The impact of the great recession on Irish air travel: An intermodal accessibility analysis. J. Air Transp. Manag. 2016, 51,1-18. [CrossRef]

17. Yang, Z.Z.; Yu, S.N.; Notteboom, T. Airport location in multiple airport regions (MARs): The role of land and airside accessibility. J. Transp. Geogr. 2016, 52, 98-110. [CrossRef]

18. Sagaris, L.; Tiznado-Aitken, I.; Steiniger, S. Exploring the social and spatial potential of an intermodal approach to transport planning. Int. J. Sustain. Transp. 2017, 11, 721-736. [CrossRef]

19. Niedzielski, M.A.; Boschmann, E.E. Travel Time and Distance as Relative Accessibility in the Journey to Work. Ann. Assoc. Am. Geogr. 2014, 104, 1156-1182. [CrossRef]

20. Redondi, R.; Malighetti, P.; Paleari, S. Hub competition and travel times in the world-wide airport network. J. Transp. Geogr. 2011, 19, 1260-1271. [CrossRef]

21. Weiss, D.J.; Nelson, A.; Gibson, H.S.; Temperley, W.; Peedell, S.; Lieber, A.; Hancher, M.; Poyart, E.; Belchior, S.; Fullman, N.; et al. A global map of travel time to cities to assess inequalities in accessibility in 2015. Nature 2018, 553, 333-336. [CrossRef] [PubMed]

22. Chen, J.; Ni, J.H.; Xi, C.B.; Li, S.Q.; Wang, J.C. Determining intra-urban spatial accessibility disparities in multimodal public transport networks. J. Transp. Geogr. 2017, 65, 123-133. [CrossRef]

23. Liu, R.; Chen, Y.; Wu, J.P.; Xu, T.B.; Gao, L.; Zhao, X.Z. Mapping spatial accessibility of public transportation network in an urban area-A case study of Shanghai Hongqiao Transportation Hub. Transp. Res. Part D Transp. Environ. 2018, 59, 478-495. [CrossRef]

24. Chow, T.E. The Potential of Maps APIs for Internet GIS Applications. Trans. Gis. 2008, 12, 179-191. [CrossRef]

25. García-Albertos, P.; Picornell, M.; Salas-Olmedo, M.H.; Gutiérrez, J. Exploring the potential of mobile phone records and online route planners for dynamic accessibility analysis. Transp. Res. Part A Policy Pract. 2018, 125, 294-307. [CrossRef]

26. Meire, S.; Derudder, B. A bimodal accessibility analysis of Australia through application programming interfaces. Transp. A Transp. Sci. 2020, 16, 695-715. [CrossRef]

27. Roma, P.; Zambuto, F.; Perrone, G. Price dispersion, competition, and the role of online travel agents: Evidence from business routes in the Italian airline market. Transp. Res. Part E Logist. Transp. Rev. 2014, 69, 146-159. [CrossRef]

28. Chuang, H.M.; Chang, C.H.; Kao, T.Y.; Cheng, C.T.; Huang, Y.Y.; Cheong, K.P. Enabling maps/location searches on mobile devices: Constructing a POI database via focused crawling and information extraction. Int. J. Geogr. Inf. Sci. 2016, 30, 1405-1425. [CrossRef]

29. Cascetta, E.; Carteni, A.; Montanino, M. A behavioral model of accessibility based on the number of available opportunities. J. Transp. Geogr. 2016, 51, 45-58. [CrossRef]

30. Saghapour, T.; Moridpour, S.; Thompson, R.G. Public transport accessibility in metropolitan areas: A new approach incorporating population density. J. Transp. Geogr. 2016, 54, 273-285. [CrossRef]

31. Abel, G.J.; Sander, N. Quantifying Global International Migration Flows. Science 2014, 343, 1520-1522. [CrossRef]

32. Simini, F.; Gonzalez, M.C.; Maritan, A.; Barabasi, A.L. A universal model for mobility and migration patterns. Nature 2012, 484, 96-100. [CrossRef] [PubMed]

33. Hou, H.P.; Liu, Y.L.; Liu, Y.F.; Wei, X.J.; He, Q.S.; He, Q.Q. Using inter-town network analysis in city system planning: A case study of Hubei Province in China. Habitat Int. 2015, 49, 454-465. [CrossRef]

34. Balcan, D.; Colizza, V.; Goncalves, B.; Hu, H.; Ramasco, J.J.; Vespignani, A. Multiscale mobility networks and the spatial spreading of infectious diseases. Proc. Natl. Acad. Sci. USA 2009, 106, 21484-21489. [CrossRef] [PubMed]

35. Yan, X.Y.; Wang, W.X.; Gao, Z.Y.; Lai, Y.C. Universal model of individual and population mobility on diverse spatial scales. Nat. Commun. 2017, 8, 1639. [CrossRef] [PubMed]

36. Wesolowski, A.; O’Meara, W.P.; Eagle, N.; Tatem, A.J.; Buckee, C.O. Evaluating Spatial Interaction Models for Regional Mobility in Sub-Saharan Africa. PLoS Comput. Biol. 2015, 11, e1004267. [CrossRef] [PubMed]

37. Xia, N.; Cheng, L.; Chen, S.; Wei, X.; Zong, W.; Li, M. Accessibility based on Gravity-Radiation model and Google Maps API: A case study in Australia. J. Transp. Geogr. 2018, 72, 178-190. [CrossRef]

38. Ren, Y.H.; Ercsey-Ravasz, M.; Wang, P.; Gonzalez, M.C.; Toroczkai, Z. Predicting commuter flows in spatial networks using a radiation model based on temporal ranges. Nat. Commun. 2014, 5, 1-9. [CrossRef] [PubMed]

39. Apparicio, P.; Abdelmajid, M.; Riva, M.; Shearmur, R. Comparing alternative approaches to measuring the geographical accessibility of urban health services: Distance types and aggregation-error issues. Int. J. Health Geogr. 2008, 7, 14. [CrossRef] [PubMed]

40. Fang, Z.X.; Yang, X.P.; Xu, Y.; Shaw, S.L.; Yin, L. Spatiotemporal model for assessing the stability of urban human convergence and divergence patterns. Int. J. Geogr. Inf. Sci. 2017, 31, 2119-2141. [CrossRef]

41. Cao, J.; Liu, X.C.; Wang, Y.; Li, Q. Accessibility impacts of China's high-speed rail network. J. Transp. Geogr. $2013,28,12-21$. [CrossRef]

42. Wu, Q.; Fan, J.; Zhang, H.; Ye, Y. The spatial impacts model of trans-strait fixed links: A case study of the Pearl River Delta, China. J. Transp. Geogr. 2017, 63, 30-39. [CrossRef]

43. Zhu, Z.; Zhang, A.; Zhang, Y. Connectivity of intercity passenger transportation in China: A multi-modal and network approach. J. Transp. Geogr. 2018, 71, 263-276. [CrossRef]

44. Kim, J.; Lee, B. More than travel time: New accessibility index capturing the connectivity of transit services. J. Transp. Geogr. 2019, 78, 8-18. [CrossRef] 
45. Civil Aviation Administration of China. CAAC Issues the Statistics Bulletin of Civil Airports in China 2017. 2018. Available online: http:/ / www.caac.gov.cn/en/HYYJ/NDBG/201804/t20180409_56273.html (accessed on 18 April 2018).

46. Center for International Earth Science Information Network-CIESIN-Columbia University. Gridded Population of the World, Version 4 (GPWv4): Population Count; NASA Socioeconomic Data and Applications Center (SEDAC): Palisades, NY, USA, 2016. Available online: http:/ / dx.doi.org/10.7927/H4X63JVC (accessed on 10 May 2018).

47. Colizza, V.; Barrat, A.; Barthelemy, M.; Vespignani, A. The role of the airline transportation network in the prediction and predictability of global epidemics. Proc. Natl. Acad. Sci. USA 2006, 103, 2015-2020. [CrossRef]

48. Tatem, A.J.; Jia, P.; Ordanovich, D.; Falkner, M.; Huang, Z.J.; Howes, R.; Hay, S.I.; Gething, P.W.; Smith, D.L. The geography of imported malaria to non-endemic countries: A meta-analysis of nationally reported statistics. Lancet Infect. Dis. 2017, 17, 98-107. [CrossRef]

49. ICAO. ICAO's Annual Report of the Council in 2016. Available online: http:/ /www.icao.int/annual-report-2016/Pages (accessed on 18 April 2018).

50. Lieshout, R. Measuring the size of an airport's catchment area. J. Transp. Geogr. 2012, 25, 27-34. [CrossRef]

51. Maertens, S. Estimating the market power of airports in their catchment areas-A Europe-wide approach. J. Transp. Geogr. 2012, 22, 10-18. [CrossRef]

52. Cui, Q.; Wei, Y.M.; Li, Y.; Li, W.X. Exploring the differences in the airport competitiveness formation mechanism: Evidence from 45 Chinese airports during 2010-2014. Transp. B Transp. Dyn. 2017, 5, 330-346. [CrossRef]

53. Guimera, R.; Mossa, S.; Turtschi, A.; Amaral, L.A.N. The worldwide air transportation network: Anomalous centrality, community structure, and cities' global roles. Proc. Natl. Acad. Sci. USA 2005, 102, 7794-7799. [CrossRef] [PubMed]

54. Lordan, O.; Sallan, J.M.; Simo, P. Study of the topology and robustness of airline route networks from the complex network approach: A survey and research agenda. J. Transp. Geogr. 2014, 37, 112-120. [CrossRef]

55. Bello-Orgaz, G.; Jung, J.J.; Camacho, D. Social big data: Recent achievements and new challenges. Inf. Fusion 2016, 28, 45-59. [CrossRef] [PubMed]

56. Gebru, T.; Krause, J.; Wang, Y.L.; Chen, D.Y.; Deng, J.; Aiden, E.L.; Li, F.F. Using deep learning and Google Street View to estimate the demographic makeup of neighborhoods across the United States. Proc. Natl. Acad. Sci. USA 2017, 114, 13108-13113. [CrossRef] [PubMed]

57. Dmowska, A.; Stepinski, T.F. A high resolution population grid for the conterminous United States: The 2010 edition. Comput. Environ. Urban Syst. 2017, 61, 13-23. [CrossRef]

58. Jia, P.; Qiu, Y.L.; Gaughan, A.E. A fine-scale spatial population distribution on the High-resolution Gridded Population Surface and application in Alachua County, Florida. Appl. Geogr. 2014, 50, 99-107. [CrossRef]

59. Wang, J.; Mo, H.; Wang, F.; Jin, F. Exploring the network structure and nodal centrality of China's air transport network: A complex network approach. J. Transp. Geogr. 2011, 19, 712-721. [CrossRef]

60. Wang, Z.B.; Xu, J.G.; Fang, C.L.; Xu, L.; Qi, Y. The study on county accessibility in China: Characteristics and effects on population agglomeration. J. Geogr. Sci. 2011, 21, 18-34. [CrossRef]

61. China Tourism Academy. 2019 Big Data Report on Outbound Tourism for the Belt and Road. 2020. Available online: http: / / www.sohu.com/a/332374202_790657 (accessed on 23 July 2020). (In Chinese).

62. China Tourism Academy and cTrip. 2017 Big Data Report on Outbound Tourism. 2018. Available online: http:/ /www.ctaweb. org/html/2018-2/2018-2-26-11-57-78366.html (accessed on 18 April 2018).

63. Du, W.B.; Zhou, X.L.; Lordan, O.; Wang, Z.; Zhao, C.; Zhu, Y.B. Analysis of the Chinese Airline Network as multi-layer networks. Transp. Res. Part E Logist. Transp. Rev. 2016, 89, 108-116. [CrossRef]

64. Zhang, Y.H.; Zhang, A.M.; Zhu, Z.R.; Wang, K. Connectivity at Chinese airports: The evolution and drivers. Transp. Res. Part A Policy Pract. 2017, 103, 490-508. [CrossRef]

65. Janic, M. Assessing some social and environmental effects of transforming an airport into a real multimodal transport node. Transp. Res. Part D Transp. Environ. 2011, 16, 137-149. [CrossRef] 